Original Article

\title{
Infant and Young Child Feeding Practices upto Two Years of Age and Their Nutritional Status
}

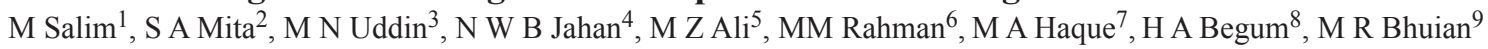

\begin{abstract}
:
This cross sectional study was conducted during the period of May 2008 to June 2009, a total of 455 mothers having their children of less than two years of age were interviewed in paediatric OPD of Sir Salimullah Medical College and Mitford Hospital to know the infants and young child feeding practices and their nutritional status. The mothers were mostly from the lower middle and poor socioeconomic condition. About one forth of the mothers had no institutional education. Most of the mothers live in a joint family. Pre-lacteal feeding rate were $60 \%$ and most common pre-lacteal food were honey and sugar water. More than $98 \%$ mothers gave colostrums to their newborn babies. Over $24 \%$ mothers initiated breast feeding within one hour and 18\% did so within 30 minutes after birth. Exclusive breastfeeding rate up to 6 completed months of age was found in only $24.4 \%$ cases and it was more in educated mothers. Continued breast feeding rate was $34.5 \%$ in 19 - 24 months age group of children. About 24\% mothers started complementary feeding timely at 6 completed months of age and about 50\% mothers started early before 6 months. Most common complementary foods were carbohydrate rich cooked suji, barley or rice powder mixed with either cow's milk or powdered milk. Only 18.5\% mother gave khichuri as a complementary food. Bottle feeding was still higher and it was $59.3 \%$ cases. In this study, $17.4 \%$ children were severely underweight and more than twenty four percent (24.4\%) was severely stunted and $2.0 \%$ were severely wasted. Malnutrition was common in those children who were nonexclusively breast fed and start complementary feeding either early or late with carbohydrate rich food.
\end{abstract}

1. Dr. Md. Salim, Medical Officer, Paediatrics Cardiology, OPD, National Institute of Cardiovascular Diseases (NICVD) Dhaka.

2. Dr. Shahina Akhter, Medical Officer, Paediatrics Cardiology, OPD, National Institute of Cardiovascular Diseases (NICVD) Dhaka.

3. Dr. M N Uddin, Assistant Professor, Department of Clinical Biochemistry, National Institute of Cardiovascular Diseases (NICVD) Dhaka.

4. Dr. NWB Jahan, EMO, Blood Bank, National Institute of Cardiovascular Diseases (NICVD) Dhaka.

5. Dr. M Z Ali, Assistant Professor, Department of Cardiology, National Institute of Cardiovascular Diseases (NICVD), Dhaka.

6. Dr. Md. Mahbubur Rahman, Assistant Professor, Department of Cardiology, National Institute of Cardiovascular Diseases (NICVD), Dhaka.

7. Dr. M A Hoque, Professor and Ex Head, Department of Paediatrics, Sir Salimullah Medical College \& Mitford Hospital, Dhaka.

8. Dr. Hosne Ara Begum, Professor and Ex Head, Department of Paediatrics, Sir Salimullah Medical College \& Mitford Hospital, Dhaka.

9. Dr. Md. Mujibur Rahman Bhuian, Ortho Trauma Surgeon

\& Director, BSMMU, Dhaka.

\section{Corresponding Author:}

Dr. Md. Salim, Medical Officer, Paediatric Cardiology OPD, National Institute of Cardiovascular diseases (NICVD), Dhaka.

\section{Introduction:}

Adequate nutrition during infancy and early childhood is fundament all development of full human potential. The period from birth to two years of age is a "critical window" for the promotion of optimal growth, health and behavioral development. ${ }^{1}$ Growth rate in human being is maximum during the first year of life and infant feeding practices comprising of both the breastfeeding as well as complementary feeding have major role in determining the nutritional status of the child. ${ }^{2}$ There are three determinants of good health, nutrition and child survival - these are food security, caring practice and disease control. Breastfeeding is an excellent example of all these three things in one. ${ }^{3}$

UNICEF and World Health Organization are working to promote breastfeeding in order to save and enrich the lives of children everywhere. ${ }^{4}$ They jointly developed "The Global Strategy for Infant and Young Child Feeding" in 2002 and recommend that children should be breastfed exclusively for the first six months of life, and then continue breastfeeding with proper complementary food up to two years of age and beyond. ${ }^{5}$ Nutritional requirements of an infant can be obtained solely from breast milk for the first six months of life. After that time breast milk must be complemented with appropriate energy-dense foods that can ensure satisfactory growth and development of the children. ${ }^{6}$ However, when the time comes to introduce foods from six months of age to complement breast milk, many young children do not receive adequate feeding. This can result in malnutrition of young children. ${ }^{7}$

Recent data from WHO showed that about $60 \%$ of all deaths, occurring among children aged less than five years in developing countries could be attributed to malnutrition. ${ }^{8}$ Causes of childhood malnutrition include IUGR (caused in large part by maternal under nutrition before and during pregnancy), poor child feeding practices and high rates of infection. ${ }^{9}$ Malnutrition is widely prevalent in children with 6-23 months age group. ${ }^{10}$

Feeding practices vary with socioeconomic condition and are regulated by a variety of factors such as education, customs, taboos, ignorance, undesirable socio cultural beliefs and misconceptions. ${ }^{11,12}$ In developed countries educated urban women are returning to breast feeding and in less developed countries such as Bangladesh the prevalence of breastfeeding, especially exclusive breastfeeding is declining. This decline is found not only among urban women but also common in rural areas where the change in practice will affect many more infants and young children. ${ }^{13}$ The Breastfeeding tradition in Bangladesh is without a doubt among the strongest in the world. However, feeding practices during the neonatal period are unsatisfactory. ${ }^{14}$ Many mothers, who initiate breast feeding satisfactorily, often start complementary feeds or stop breast feeding within a few weeks of delivery. In addition, many children, even those who have grown well for the first six months of life, do not 
receive adequate complementary feeds. ${ }^{15}$ Since mid-sixties, several quantitative and qualitative studies have been conducted in several communities and hospitals in Bangladesh trying to identify infant feeding practice. ${ }^{16}$ These studies have identified serious problems in feeding practices $\&$ their nutritional status especially in underprivileged area. ${ }^{17,18,19}$

In our study the patients of the Mitford Hospital are coming from underprivileged older part of Dhaka city, slum area around Kamrangir Char \& Keranigonj. The socioeconomic condition and educational level is low in this part of Dhaka. So far our knowledge there is no such study in this area. So in this study an attempt was made to evaluate the current infant and young child feeding situation as well as their nutritional status and see any relationship between infant feeding practices and their nutritional status. The study findings would be helpful for the intervention program in infant and young child feeding practices \& thus help to achieve the millennium development goal.

\section{Materials and Methods:}

Setting: This cross sectional study was conducted in Sir Salimullah Medical College \& Mitford Hospital, Dhaka from May 2008 to June 2009.

Inclusion Criteria: Children upto 2 years of age who were attended the paediatric OPD, ORT corner and EPI centre of Sir Salimullah Medical College \& Mitford Hospital.

Exclusion Criteria: Very sick children (feature of very severe disease), Children without their mother and Handicapped children were excluded from this study.

Sampling: Children up to 2 years of age, who fulfilled the inclusion and exclusion criteria and those mothers who gave the informed voluntary consent to participate in the study were enrolled. A total of 455 consecutive children upto two years of age of both sexes were enrolled for this study. Purposive sampling method was followed for the collection of sample.

Instrument and Data collection: A simple questionnaire was used for the data collection by the investigator himself. Before collection of data, the questionnaire was translated into a local language to ensure all participants understood the question asked in the survey. The questionnaire incorporated questions related to demographic information, feeding history and examination related question. Examination includes anthropometric measurement and bilateral pedal edema determined. Finally weight for age, height for age and weight for height was calculated in both percentile and $\mathrm{Z}$ score and recorded in the questionnaire. We used the definition of malnutrition by using the WHO values ( $Z$ score and presence or absence of bilateral symmetrical edema) and plotted different grades of malnutrition.

Data Analysis: Analysis of data was done in accordance with the objectives of the study. Statistical analysis was performed using SPSS software version 11.5. Data were tabulated and prepared univariate or bivariate tables. Then simple statistics for sociodemographic, feeding and anthropometric variables was done concerning percentage, mean, median, mode and standard deviation. Chi-squared test was used to see the statistical difference among the sociodemographic, feeding and anthropometric variables. A probability level ( $p$ value) of less than 0.05 was considered as significant and less than 0.001 was highly significant.

\section{Results:}

Demographic data: A total 455 mothers with their same number of children were interviewed during this study period with a response rate of $100 \%$. Maximum children were in between the age of 7 to 18 months of age group (56.5\%). Male and female ratio almost equal. Among 455 respondents $39.8 \%$ from urban area, $11 \%$ from rural area and rest of them from semi-urban area. $21.3 \%$ mother had no institutional education and $41.1 \%$ had the educational level secondary or above. Most of the mothers were housewives (97.8\%). Monthly family income were Tk. $4000-8000$ in $43.7 \%$ families and more than $8000 \mathrm{Tk}$ in $40.2 \%$ families. Most families $(59.8 \%)$ in this area live in a joint family.

Initiation of breast feeding after child birth: Most of the mothers $(98.2 \%)$ reported that they gave colostrums to their newborns. Only 1.8\% mothers expressed out colostrums according to the advice of their elder member of the family. Over 24\% mothers reported breast feeding to their babies within one hour after birth and among them $18.1 \%$ did so within 30 minutes after birth. $44.4 \%$ of them initiate breast feeding after first hour but within 12 hours after birth. About $11 \%$ mothers reported initiation of breast feeding one day after delivery. Early initiation was more common among educated mother ( $\mathrm{p}<0.001) .60 \%$ mother gave their newborn pre-lacteal food before giving breastfeeding. Most common (89.4\%) prelacteal food was sugar water, honey or misree water.

Prevalence of Exclusive breast feeding: Table I showed that $24.4 \%$ children were exclusively breastfed for 6 completed months which was recommended by WHO. But most of the children (46.4\%) were exclusively breastfed for 3 months or less. Mothers having secondary or above educational level were more conscious to give their babies exclusive breast feeding.

Table I: Distribution of children by duration of EBF. (mean $\pm \mathrm{SD}=3.2 \pm 2.3$ )

\begin{tabular}{|l|c|c|}
\hline Duration of EBF & Frequency & Percentage \\
\hline$<1$ month & 76 & 17.3 \\
\hline $1-3$ months & 204 & 46.4 \\
\hline $4-5$ months & 52 & 11.8 \\
\hline 6 completed & 108 & 24.5 \\
\hline months \& beyond & & \\
\hline Total & 440 & 100.0 \\
\hline
\end{tabular}

N.B. 15 children did not get EBF 
receive adequate complementary feeds. ${ }^{15}$ Since mid-sixties, several quantitative and qualitative studies have been conducted in several communities and hospitals in Bangladesh trying to identify infant feeding practice. ${ }^{16}$ These studies have identified serious problems in feeding practices $\&$ their nutritional status especially in underprivileged area. ${ }^{17,18,19}$

In our study the patients of the Mitford Hospital are coming from underprivileged older part of Dhaka city, slum area around Kamrangir Char \& Keranigonj. The socioeconomic condition and educational level is low in this part of Dhaka. So far our knowledge there is no such study in this area. So in this study an attempt was made to evaluate the current infant and young child feeding situation as well as their nutritional status and see any relationship between infant feeding practices and their nutritional status. The study findings would be helpful for the intervention program in infant and young child feeding practices \& thus help to achieve the millennium development goal.

Materials and Methods:

Setting: This cross sectional study was conducted in Sir Salimullah Medical College \& Mitford Hospital, Dhaka from May 2008 to June 2009.

Inclusion Criteria: Children upto 2 years of age who were attended the paediatric OPD, ORT corner and EPI centre of Sir Salimullah Medical College \& Mitford Hospital.

Exclusion Criteria: Very sick children (feature of very severe disease), Children without their mother and Handicapped children were excluded from this study.

Sampling: Children up to 2 years of age, who fulfilled the inclusion and exclusion criteria and those mothers who gave the informed voluntary consent to participate in the study were enrolled. A total of 455 consecutive children upto two years of age of both sexes were enrolled for this study. Purposive sampling method was followed for the collection of sample.

Instrument and Data collection: A simple questionnaire was used for the data collection by the investigator himself. Before collection of data, the questionnaire was translated into a local language to ensure all participants understood the question asked in the survey. The questionnaire incorporated questions related to demographic information, feeding history and examination related question. Examination includes anthropometric measurement and bilateral pedal edema determined. Finally weight for age, height for age and weight for height was calculated in both percentile and $\mathrm{Z}$ score and recorded in the questionnaire. We used the definition of malnutrition by using the WHO values ( $\mathrm{Z}$ score and presence or absence of bilateral symmetrical edema) and plotted different grades of malnutrition.

Data Analysis: Analysis of data was done in accordance with the objectives of the study. Statistical analysis was performed using SPSS software version 11.5. Data were tabulated and prepared univariate or bivariate tables. Then simple statistics for sociodemographic, feeding and anthropometric variables was done concerning percentage, mean, median, mode and standard deviation. Chi-squared test was used to see the

\section{Prevalence of continuation of Breast feeding:}

Table II: Distribution of children by continuation of breast feeding by age group $(n=350)$

\begin{tabular}{|l|c|c|}
\hline Age group & Frequency & Percent \\
\hline $7-12$ months & 93 & 69.9 \\
\hline $\begin{array}{l}13-18 \text { months } \\
(\mathrm{n}=124)\end{array}$ & 61 & \\
\hline $\begin{array}{l}19-24 \text { months } \\
(\mathrm{n}=93)\end{array}$ & 32 & \\
\hline
\end{tabular}

In 19 - 24 months age group $34.5 \%$ children continued breast feeding along with complementary feeding as recommended by World Health Organization. But it also showed that continuation of breast feeding from 7 months onward was declining.

Complementary feeding: Among the total 455 children, 68 children of 0 - 6 months age group were not yet started complementary feeding as recommended. Among 387 children $23.8 \%$ started complementary feeding timely at 6 completed months (after 180 days). About half of the children $(47.8 \%)$ were initiated complementary feeding early before 6 months and more than 28\% were initiated delayed after 7 months of age. Timely initiation of complementary feeding was more common in those mothers who had secondary or above educational level. Among complementary foods, majority $(32.3 \%)$ reported giving cooked suji, barley or rice powder mixed with milk, either cow's milk or powdered milk. The next major proportion of mothers (18.5\%) reported Khichuri. Another 17.1\% mother gave only suji or barley or rice powder without milk, cooked water and salt. Mixed family foods such as rice, fish, meat, eggs, vegetables were reported only 5.5\% mother. Artificial baby food, Cerelac were given by about $6 \%$ mothers.

Table III: Distribution of children between $0-24$ months of age by timing of start of complementary feeding $(n=387)$

\begin{tabular}{|l|c|c|}
\hline $\begin{array}{l}\text { Timing of start of } \\
\text { CF }\end{array}$ & Frequency & Percent \\
\hline$<6$ month & 185 & 47.8 \\
\hline $\begin{array}{l}\text { Timely at 6 } \\
\text { completed } \\
\text { months }\end{array}$ & 92 & 23.8 \\
\hline$>7$ months & 110 & 28.4 \\
\hline Total & 387 & 100.0 \\
\hline
\end{tabular}

Prevalence of Bottle feeding: Bottle feeding 
was reported by $59.3 \%$ mothers. It was higher among rural and semi-urban mothers than those of urban mothers. It was also common among those mothers who had no institutional education or had only primary level education.

Nutritional status of the Children: Among 455 children 362 (79.6\%) were underweight and among them $17.4 \%$ (79 children) were severely underweight, 374 children (82.2\%) were stunted, among them 24.4\% (111 children) were severely stunted and 174 children $(38.2 \%)$ were wasted, among them $2 \%$ (9 children) were severely wasted. $11.6 \%$ $(n=53)$ children presented with bilateral symmetrical pedal edema which was associated with severe protein energy malnutrition.

Table IV Distribution of children by type of breast feeding and their selected parameters of nutritional status $(n=440)$

\begin{tabular}{|l|c|c|c|l|}
\hline $\begin{array}{l}\text { Selected } \\
\text { parameters }\end{array}$ & EBF & $\begin{array}{c}\text { Not } \\
\text { EBF }\end{array}$ & Total & Statistics \\
\hline Height for & 5 & 101 & 106 & $\mathrm{X}^{2}=70.1$ \\
age & 27 & 107 & 134 & $\mathrm{df}=9$ \\
$-<3$ SD & 40 & 79 & 119 & $\mathrm{p}<0.001$ \\
-2 to -3 SD & 36 & 45 & 81 & \\
-1 to -2 SD & & & & \\
$>-1$ SD & 3 & 6 & 9 & $\mathrm{X}^{2}=49.8$ \\
\hline Weight for & & 42 & 46 & $\mathrm{df}=9$ \\
Height & 10 & 105 & 115 & $\mathrm{p}<0.001$ \\
$-<3$ SD & 91 & 179 & 270 & \\
-2 to -3 SD & & & & \\
-1 to -2 SD & 9 & 44 & 46 & $\mathrm{df}=3$ \\
$>-1$ SD & & 288 & 394 & $\mathrm{p}<0.001$ \\
\hline Pedal & & & & \\
edema & 2 & & \\
Present & 106 & & \\
Absent & & & \\
\hline
\end{tabular}

Table IV showed that the number of malnutrition (stunting, wasting and bilateral symmetrical edema which is a sign of severe malnutrition) were higher among nonexclusively breastfeeding children.

Table V Distribution of children by initiation of complementary feeding and their selected parameters of nutritional status.

\begin{tabular}{|l|c|c|}
\hline Selected parameters & Early (<6 months) & $\begin{array}{c}\text { Timely at 6 completed } \\
\text { months }\end{array}$ \\
\hline $\begin{array}{l}\text { Ht for age } \\
-<3 \text { SD }\end{array}$ & 67 & 5 \\
-2 to -3 SD & 63 & 21 \\
-1 to -2 SD & 38 & 36 \\
$>-1$ SD & 17 & 30 \\
\hline Wt for Ht & & 0 \\
$-<3$ SD & 4 & 3 \\
-2 to -3 SD & 30 & 11 \\
-1 to -2 SD & 69 & 78 \\
$>-1$ SD & 82 & 3 \\
\hline Pedal edema & & 89 \\
Present & 41 & \\
Absent & 144 & \\
\hline
\end{tabular}

It was also showed that (Table V) the number of malnutrition (stunting and wasting) was common in those children, who were not initiated complementary feeding timely, either early or delayed initiation. Bilateral symmetrical pedal edema was higher among those children who were initiated complementary feeding early at or before six months of age. It also showed that the number of malnutrition (stunted, wasted and/or bilateral pedal edema) was more among those children who were given complementary feeding with suji, barly, rice powder with or without mixed with milk than those children who were given complementary feeding with khichuri and mixed family food. It was statistically highly significant.

\section{Discussion:}

Bangladesh is traditionally a breastfeeding country, but it is strange to see that the majority of protein energy malnutrition (PEM) cases are less than one year of age14. This picture dose not reflects the successful breastfeeding practice of the country. The present study was done on 455 children of less than two years of age in the out patient department of Sir Salimullah Medical College and Mitford Hospital, Dhaka to know the feeding practices and their nutritional status.

It was found from the study that exclusively breastfeeding rate was only $24.4 \%$. It was higher in educated mothers who have completed at least SSC examination. BDHS preliminary report (2007)20 showed that exclusive breast feeding rate was $43 \%$. It is higher than our study. Another study showed that exclusive breast feeding rate was $12 \%$ among urban affluent of Dhaka. The reason given by most women for not exclusive breastfeeding is insufficient milk. 
This is not due to the poor nutritional status of mothers but it is a psychosocial problem. ${ }^{21}$ The NNP baseline survey using a strict definition of EBF showed, exclusive breastfeeding rate was $12.8 \%$ and another study of ICDDRB showed EBF rate only $15 \% .{ }^{8}$ Another study in Narayangong. ${ }^{22}$ showed that exclusive breastfeeding rate was $51.8 \%$. The difference of these findings indicates the gradual increase in exclusive breastfeeding practices. This gradual increase is due to vigorous campaign regarding promotion and protection of breastfeeding. But in our study area exclusive breast feeding rate was lower than the national study. It may be due to less educational rate in this area, traditional customs and belief, and over all lack of knowledge about the benefit of breast feeding to their babies.

Pre-lacteal feeding rate was found $60 \%$ in this study and most of the mother gave pre-lacteal food in the form of honey, sugar water, misree water glucose etc. In the BIRPERHT study ${ }^{16}$ it was $89 \%$ and 12 round surveys ${ }^{19}$ it was $61.6 \%$. Pre-lacteal feeding rate was a bit less in our study. In the Middle East a study in Libya showed that $18.5 \%$ mother gave their newborn pre-lacteal foods in the form of honey, glucose water and extract of leaves. ${ }^{23}$

Our study showed a higher rate of colostrums administration. In the BIRPERHT study. ${ }^{16}$ prevalence of colostrums given to the newborn was $71.2 \%$. Another national survey in Bangladesh showed about $78 \%$ of mother gave colostrums to their newborn. ${ }^{7}$ But the timing of initiation of breast feeding varied among the mothers in this study. About 24\% mothers initiate breast feeding within one hour after birth, among them 18\% mothers initiate within first 30 minutes after birth. Early initiation of breast feeding was more prevalent in educated mother. Recent research shows that about 4 million newborn deaths occur every year globally, 22\% of these deaths could be prevented if newborns initiated breastfeeding within one hour of birth. ${ }^{24}$

In this study $23.8 \%$ children started complementary feeding along with breast feeding timely at 6 completed months. It was more common in educated mothers. BDHS preliminary report (2007). ${ }^{20}$ showed $74 \%$ infant started complementary feeding timely at 6 completed months which was higher than that of our study. One study in Dhaka showed 69.9\% mother start complementary feeding before reaching six month of age. ${ }^{25}$ Timely started complementary feeding of some studies showed 50\% infant in the Rangpur Medical College Hospital study. ${ }^{19} 69.6 \%$ infant in Rajshahi Medical College Hospital study. ${ }^{26}$ In India mothers started complementary feeding delayed due to religious reason. ${ }^{27}$ In Pakistan a study showed that $25 \%$ infants started complementary feeding timely. ${ }^{23}$ In Malaysia $28.3 \%$ infants started early before 4 months and timely started complementary feeding in $12.8 \%$ of infants. In Britain $90 \%$ mother started complementary feeding by the age of 4 months. ${ }^{9}$

Most of the mothers (32.3\%) in this study started complementary feeding with cooked suji, barley or rice powder mixed with milk, either cow's milk or powdered milk. Another $17.1 \%$ mothers gave only suji or barley or rice powder, cooked with water and salt without milk, which was carbohydrate rich low energy diet. It showed that most of the infants of this region took low energy diet when they need nutritious food for their growth and development. In the BIRPERHT study ${ }^{16} 58.7 \%$ mother gave khichuri as a starting complementary diet. In 2000 the Nutrition Surveillance Project (NSP) reports showed that many children were given complementary foods such as gruels and other liquids before six months of age. $20 \%$ of infants aged 6 months were given family foods as the main component of their diet, a percentage which rises to $56 \%$ among infants aged 9 months and reaches $87 \%$ among infants aged 12 months. It also reveal that about $60 \%$ of infants aged between 6 and 11 months old had not given either fish, egg, dal, green leafy vegetables or yellow or orange fruit or vegetables, compared with less than $1 \%$ of their mothers. ${ }^{7}$ This finding is similar to our study.

Bottle feeding rate was higher in our study, it showed that $59.3 \%$ mother used feeding bottle for feeding their infant either liquid or semisolid food. The rate was higher among rural and semi-urban mothers and also higher in those mothers with no institutional education or had only primary level education. Other studies showed bottle feeding rate were $27.1 \%$ in Rajshahi Medical College study. ${ }^{26} 17.6 \%$ in BIRPERHT study. 16

In this study, the rate of continued breast feeding along with complementary feeding among 19 - 24 months age group children showed $34.5 \%$. In 7 - 12 month age group most $(69.9 \%)$ of the mothers and 13 - 18 months age group about $50 \%$ mothers continued breast feeding to their children at the time of interview. The Nutrition Surveillance Project (NSP)7 reports showed that continued breastfeeding rate up to two years of age was $85 \%$ and up to 1 year of age was $96 \%$. The 12 round surveys ${ }^{28}$ found that $95 \%$ children up to 1 year and $82.7 \%$ children up to two years of age continued breastfeeding. The BDHS preliminary report (2007)20 found $91 \%$ children continued breastfeeding up to two years of age. Nutritional status of the children in this study found that $17.4 \%$ were severely underweight, $24.4 \%$ were severely stunted and $2.0 \%$ were severely wasted. In this study $11.6 \%$ $(n=53)$ children presented with bilateral symmetrical pedal edema which was associated with severe protein energy malnutrition. Wasting, stunting, underweight and bilateral pedal edema were mostly prevalent in nonexclusively breast fed children. Severe stunting and wasting were common in those children who started their complementary feeding early before 6 months of age or delayed after 7 months of age. Bilateral pedal edema was more common in those children who started complementary feeding early before 6 months of age. The children who started complementary feeding with carbohydrate rich diet was stunted, wasted and under weight and also had bilateral pedal edema. But the children who started complementary feeding with khichuri and mixed food were more or less nutritionally well.

A study in Rangpur Medical college Hospital ${ }^{19}$ found $7.2 \%$ children up to two years of age suffered from severe malnutrition. One study in the six division of Bangladesh showed that $38.1 \%$ were stunted and $38 \%$ were underweight for their age. Only 19.55 of exclusively breastfed children were underweight where as $41.4 \%$ of non-exclusive breastfed children were underweight for their age. Children 
aged 13-24 months were 2.8 times more likely to be stunted than the children aged 0-12 months. ${ }^{29}$ The BDHS preliminary report (2007)20 showed that $36 \%$ were stunted while $16 \%$ were severely stunted. Children of mothers with no education were more than twice as likely to be stunted as children of mother who had secondary and higher education. $16 \%$ children were wasted and $3 \%$ were severely wasted. Wasting peaks at the age of $10-11$ months of age, it was consistent to our result. $46 \%$ were underweight and $12 \%$ were severely underweight. Another study in India30 found that prevalence of underweight, stunting and wasting in $0-6$ months of age were $22.6 \%, 32.3 \%$ and $8.1 \%$ respectively. Compared to those of $6-12$ months of age were $64.6 \%$, $41.7 \%$ and $39.6 \%$ respectively. Our results are more or less close those study.

\section{Conclusion:}

In this study area feeding practices among the infants and young children was not satisfactory when compared with the other national and international study. IYCF recommendation was poorly followed. Bottle feeding rate was still high. Malnutrition was common among those children who were not exclusively breastfed and those did not started complementary feeding timely with appropriate complementary foods. It was more common in those children whose mother has no institutional education. So it is recommended that improvement of maternal education and breastfeeding and complementary feeding campaign through different strategies should be further strengthened to improve this situation.

\section{References:}

1. Pan American Health Organization and World Health Organization (PAHO \&WHO). Guiding Principles for complementary feeding of the breastfeed child. 2003; PAHO \&WHO,

2. Washington DC: 2.

Ministry of Human Resource development. National Guidelines on Infant and Young Child Feeding (IYCF), Government of India 2004;

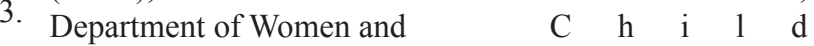
Development ( Food and Nutrition Board): 1-26.

Talukder MQK. Breastfeeding: Healthy Mothers and Healthy Babies. World Breastfeeding Week 2002; DHAKA:1-3. Bangladesh Breast Feeding Foundation,

5. Roy SK, Ireen S, Rahman S. Why Breast feeding is

6. Important? World Breastfeeding Week 2002; DHAKA: 4-6. Bangladesh Breast Feeding Foundation,

7. World Health Organization. Global Strategy for Infant and Young Child Feeding. WBW 2003; WHO, Geneva: $1-8$.

8. Food and Nutrition Research Institute. Nutritional Guidelines for Filipinos 2000; Metro Manila, Philippines: 1-7.

Institute of Child and Mother Health. Training on Complementary Feeding under HNPSP 2006;
9. Ruel MT, Brown KH, Caulfield LE. Moving forward with Complementary Feeding : Indicators and

Research Priorities. Food

Consumption and Nutrition Division

Discussion paper 146. International Food Policy

10. 2003; Washington DC: 1.

Tasnim S, Afroza S, Rahman F. Sociodemographic characteristics and enrollment criteria of under

2 children in Food supplementation

11. programme under BINP. Bangladesh J Child Health 2004; 28 (2): 40-44.

Nagra S A, Gilani A H. Variation in infant feeding

12. practices in Pakistan with socioeconomic stratification. J Trop Paed $1987 ; 33$ : 103-106.

Tiwari R, Mahajan PC, Lahariya C. The Determinants

13. of Exclusive Breast Feeding in Urban Slums: A Community based study. Journal of Tropical Pediatrics 2008; 55(1): 49-54.

14. Ahmed S, Archer S, Islam A, Bloem M. Infant Feeding Practices in Bangladesh:The Dhaka-Narayanganj Study of 1989. Bangladesh J Child Health

15. 1999; 23 (1/2): 6-11.

Greiner T. One of the most intact breastfeeding cultures in the world: Bangladesh. Bangladesh Journal of

16. Nutrition 1996; 1: 10.

World Health Organization. Infant and Young Child Feeding Counselling:An Integrated Course, 17. Participant's Manual 2006; WHO, Geneva: 1-5.

Akhter HH. A National baseline survey to assess the

18. breast feeding practices in Bangladesh. 1998; BIRPERTH Dhaka: 1-4.

Talukder MQK, Kawser CA. Growth pattern of exclusively Breastfed Infants. Bangladesh J Child Health 1986; 10(2): 59-65.

19. Ferdousi I, Rahman F. Socio-demographic characteristics of under 2 years children requiring food supplementation under BINP in rural community of two selected Thanas. Bangladesh J Child Health 2003; 27

20. 70-75.

Wahed MA, Islam MA. Pattern of Breast feeding, Nutritional status and morbidity from Pneumonia. In: 1st National Conference.

21. Achieving Millennium

Development Goal 4 and 5: Where we are and what needs to be done. 2007; ICMH, Dhaka: 88 .

22. National Institute of Population Research and Training (NIPORT). Bangladesh Demographic and Health Survey 2007; Mitra and Associate Dhaka and ORC Macro USA: 30-34.

Talukder MQK, Kabir SM, Talukder SY. Problems in

23. Breastfeeding and their management. Bangladesh J Child Health 1992; 16(1/2): 37-48.

Wahida K, Haque M A, Rahman N, Khatoon S, Hannan 
24. Bangladesh Breast Feeding Foundation. Breast feeding : $\quad$ Initiation in the 1st Hour can save more than one million new born. World Breastfeeding Week 2007; BBF,

25. Dhaka: 14.

Giashuddin M S, Kabir M. Duration of

26. breastfeeding on Res 2004; 119: 267-272.

Haque M I. Assessing Breast feeding practice using

27. WHO indicators 2005; Dissertation. Rajshahi Medical College and Hospital, Bangladesh: 65.

Bhardwaj N, Hasan B S, Zaheer M. Breast-Feeding and
28. Hannan A, Rahman F, Rahman A, Hassan M Q, Talukder M Q K, Roy S K. Surveillance of breastfeeding and weaning situation and child

and maternal health in Bangladesh report

of 12 th round

survey. In: 1 st

National Conference. Achieving

Millennium Development Goal 4 and 5: Where we are

29. and what needs to be done. 2007; ICMH, Dhaka: 88.

Giashuddin M S, Kabir M, Rahman A, Hannan M A.

30. Exclusive Breastfeeding and Nutritional Status in $471-475$. 